\title{
LA IDEA DE FELICIDAD EN EL PENSAMIENTO DE JOVELLANOS
}

Marc Marti ${ }^{7}$

Mientras que en Francia existe una tesis sobre el tema de la felicidad en el siglo XVIII, este ha sido objeto de menos investigaciones en España ${ }^{2}$. Hay sin embargo trabajos precursores que dedican unas páginas al tema, como los de M.C. Seoane y R. Lapesa ${ }^{3}$. En los años setenta, J.A. Maravall publico un extenso artículo sobre esta materia, que se integraba en su amplia reflexión sobre los conceptos claves de la llustración ${ }^{4}$. Más recientemente, el libro de P. Álvarez de Miranda, que enfoca el ideario de la llustración temprana (1680-1759) a través de su vocabulario, propone un estudio del concepto de felicidad $^{5}$. No existe sin embargo un trabajo global semejante al de R. Mauzi y por otra parte, excepto el valioso estudio de P. Álvarez de Miranda, tampoco la evolución en el tiempo de los conceptos es realmente estudiada, aunque J.A. Maravall señala en su conclusion una evolución semántica de la palabra felicidad ${ }^{6}$.

La aparente ausencia de un trabajo global se explica por varios factores. Primero, los prejuicios forjados por la historiografía decimononica retrasaron el interés por el siglo. Luego, si comparamos — porque creemos que la comparación es necesaria si se quieren notar las peculiaridades nacionales-, la producción francesa sobre la felicidad con los escritos en castellano, las diferencias son enormes. En efecto, para su tesis, Mauzi utilizo un número impresionante de tratados, reflexiones, disertaciones de la epoca, mientras que en España, según la bibliografía de F. Aguilar Piñal, solo podemos encontrar 37

1. Maître de Conférences de literatura y de civilización hispánica (siglo XVIII) en la Universidad de Niza (Francia), Facultad de Letras, Departamento de Español. Miembro del equipo de investigación del Centro de Narratología Aplicada (CNA) de la Universidad de Niza.

2. MAUZI, R., 1960.

3. SEOANE, M.C., 1968, LAPESA, R., 1968.

4. J.A. MARAVALL, 1974.

5. P. ÁLVAREZ DE MIRANDA, 1992.

6. J.A. MARAVALL, 1974, p. 458-460. 
escritos que incluyen la palabra "felicidad" en el título, entre los cuales algunos son manuscritos de escasa extension y otros son traducciones u obras literarias. Esta segunda explicacion, la de la "pobreza" de la reflexion filosofica española, se explicaría por el vigor de las diferentes censuras, cuanto más tratándose de un tema que podía oler a heterodoxia. Fue el caso por ejemplo de la traducción que publico el teniente coronel Bernardo María de Calzada, Discurso sobre cuanto contribuye a la felicidad de los estados el respetar las costumbres, en 1786. El texto fue prohibido "por fomentar el tolerantismo y el libertinaje, por edicto del 9 de julio de 1796"7. Sin embargo, no podemos creer que la filosofía y la reflexión sobre la condición del hombre no existio en la península. Proponemos entonces aquí encontrarla donde hay que esperarla y como lo hicieron los que trabajaron sobre el ideario de la llustracion: en la literatura pragmática tan abundante en España, la de los ensayos sobre educacion, informes sobre economía y política ${ }^{8}$. Por otra parte, no explicaremos aquí la formación del concepto de felicidad así como la historia del lexico derivado. Todo cuanto se refiere a este tema se puede encontrar en las primeras páginas de J.A. Maravall y en el capítulo sobre la felicidad del libro de P. Álvarez de Miranda ${ }^{9}$. Sin embargo, antes de adentrarse en el estudio, es necesario reflexionar sobre el método más adecuado para el análisis de un concepto que forma parte del vocabulario de la llustracion.

La utilización de la lingüística como herramienta de análisis podría ser provechosa para el historiador ${ }^{10}$. El primer libro de referencia fue el de G. Matoré, el creador de la lexicología como "ciencia histórica"11. El modelo propuesto por Matoré fue completado por J. Dubois en 1962 y finalizado en un artículo de 1969 ${ }^{12}$. Esas propuestas fueron seguidas en España por los estudios sobre las relaciones entre el léxico y la historia como los de P. Álvarez de Miranda y el de P. Peira ${ }^{13}$.

Por parte de los historiadores, R. Robin, en Histoire et linguistique, publicado en 1973, cuando ya se daban los primeros análisis del léxico con la ayuda de computadoras, subrayaba con lucidez las ventajas pero también las limitaciones de la lingúística al analizar los textos desde la perspectiva historica. La principal crítica a métodos de tipo lexicologico que hizo la historiadora francesa era que permitían fechar de manera acertada la emergencia de un tipo de vocabulario pero no las posibles evoluciones semánticas de las palabras en el tiempo ${ }^{14}$. Por otra parte, nada indicaba que existiera una perfecta adecuación

\footnotetext{
7. AGUILAR PINAL, F, véase la letra "C".

8. Vease el trabajo sobre Campomanes de SOUBEYROUX, J., 1997.

9. MARAVALL, J.A., 1973, pp. 425-426; ÁLVAREZ DE MIRANDA, P., pp. 272-273.

10. Para un estado de la cuestion sobre las posibilidades de la lingüística en las ciencias humanas, véase, MAINGUENEAU, D., 1995.

11. MATORÉ, G., 1953.

12. DUBOIS, J., 1962 y 1969.

13. ÁlVAREZ DE MIRANDA, P., 1992; PEIRA, P., 1977.

14. Sobre el interés del neologismo en la historia de las ideas, ARGOMATHE, J.R., 1973.
} 
entre un grupo social preciso y una serie de palabras específicas ${ }^{15}$. En el caso de la llustración, F. Lopez ya señalaba, en 1973, que tras la aparente homogeneidad del vocabulario debida al fondo común del léxico, existían tendencias ideologicas totalmente opuestas. Una de las posibles soluciones para este problema la propuso J. Soubeyroux, siguiendo las orientaciones de M. Foucault ${ }^{16}$. Para él, "las palabras solo se pueden analizar dentro de los sistemas semioticos que se usan en cada época, y [...] estos dependen estrechamente de las prácticas discursivas, de las posiciones ideológicas de aquéllos que intervienen en el proceso de su produccion y de las condiciones sociales de su enunciación"17. Así, el estudio que proponemos a continuación utilizará la obra de Jovellanos, en la que se conoce al enunciador y se le puede situar social y políticamente. Por otra parte, se ha de proceder a un análisis dentro del marco de los "géneros" ensayísticos, algo imprescindible ya que la misma palabra de "felicidad" tendrá sentidos diferentes según se encuentre en un informe economico o una reflexión ética. Dejando aparte sus obras literarias y relaciones de viajes, que fueron objeto de varios trabajos, nos interesaremos por los informes, memorias y ensayos redactados por el asturiano. El proyecto pudiera parecer poco original considerando la cantidad de estudios publicados sobre estos escritos, pero ninguno analiza detalladamente la concepción que Jovellanos tuvo de la felicidad, a pesar de que él recurriese a menudo a este concepto para justificar planes de reformas o proyectos de mejoras.

\section{La base de un pensamiento político y economico}

Las ideas políticas de Jovellanos fueron estudiadas en un trabajo importante que subraya la pertenencia del asturiano a una corriente reformista, nada revolucionaria en el terreno político, aunque haya utilizado el lenguaje "liberal-ilustrado" según el término utilizado por el propio autor ${ }^{18}$. L. Domergue, en un artículo reciente, también insistio en el hecho de que el asturiano no era un profeta del liberalismo sino más bien un pensador pragmático ${ }^{19}$. Por nuestra parte, habíamos intentado demostrar como el "liberalismo" y la doctrina "liberal" contenida en el Informe sobre la ley agraria no seguía exactamente la línea teorica de Adam Smith ${ }^{20}$. Se trataba más de una adaptación práctica a la realidad española, en la que Jovellanos hacía hincapié en los análisis del escocés que eran compatibles con un status quo social, o por lo menos nada que modificase el poder economico de la nobleza terrateniente. Esto no impedía la utilización del léxico forjado por el padre del liberalismo. Concluíamos que la doctrina defendida por Jovellanos parecía paradójica, y que se trataba de un

\footnotetext{
15. ROBIN, R., 1973b, p. 114.

16. FOUCAULT, M., 1969.

17. SOUBEYROUX, J., 1984, p. 115.

18. BARAS ESCOLÁ, F., 1993, p. 13.

19. DOMERGUE, L., 1997, p. 94

20. MARTI, M., 1997.
} 
"Iiberalismo de compromiso"21. Este resultado nos acercaba a la posición de F. Baras Escolá para quien "la Ilustración era una variante lingưística susceptible de rendir servicios a la propaganda reformista. Surge entonces un segundo concepto de llustración, destinado exclusivamente a legitimar una determinada línea de acción política" 22 .

Quisiéramos aquí matizar y completar este juicio que compartimos estudiando precisamente el concepto de felicidad tal como aparece en el pensamiento de Jovellanos.

Para él, como para los ilustrados que formaron parte de la élite que accedio a los puestos claves del Estado, el concepto de felicidad no era de ninguna manera subversivo. Era claramente reivindicado como proyecto de gobierno ya que "la política considerada como el arte de gobernar los pueblos, no puede tener otro que el de su felicidad"23. De esta primera asercion se derivaba la conclusion de que el mejor sistema de gobierno era el que proporcionaba la felicidad a todos:

"Toca también a la política perfeccionar la legislación, pues que de ella pende principalmente la felicidad de los pueblos, y esto en tanto grado que, cuando las leyes son buenas, la Constitución viene a ser indiferente para ellos, porque es protegida la propiedad y la libertad del ciudadano, donde nada puede turbar su quietud y seguridad, ¿qué le importa ser mandado por uno, por algunos, o por una muchedumbre?"24.

Aspirar a la felicidad no podía ser subversivo ya que esta no dependía de un sistema de gobierno preciso, lo que en el discurso político oficial de aquel entonces significaba que la monarquía absoluta era perfectamente compatible con dicha aspiracion.

Así, partiendo de este principio general, se derivaba la organización política del Estado absolutista en la que en cada nivel de poder se trabajaba por la felicidad del pueblo. Primero, en lo más alto estaba la familia reinante, cuya multiplicación significaba la felicidad de los súbditos. En el discurso muy oficial de felicitacion a Carlos III con motivo del nacimiento de sus nietos los dos infantes don Carlos y don Felipe, Jovellanos indica que la "maravillosa fecundidad" de María Luisa "nos asegura y multiplica los apoyos del trono, y con ellos la pública felicidad" 25 . En este caso también se pensaba en la paz que significaba el hecho de disponer de varios herederos para la corona, en un país donde el principio del siglo había coincidido con una dura guerra de

21. MARTI, M., 1997, pp. 201-202.

22. BARAS ESCOLÁ, F., 1993, p. 13

23. JOVELLANOS, 1951-56, BAE, vol 87, "Introducción a un discurso sobre la economía civil", p. 11a-b.

24. JOVELLANOS, G.M., 1951-56, BAE, "Introducción a un discurso sobre la economía civil", p. 11a-b.

25. JOVELLANOS, G.M., 1951-56, BAE, vol. 46, "Felicitacion a Carlos III con motivo del nacimiento de sus nietos los dos infantes don Carlos y don Felipe", p. 305b. 
sucesion. Pero hemos de notar en seguida que Jovellanos se valio muy poco de la imagen, muy usada en el reinado de Carlos III, según la cual el monarca hacía directamente la felicidad de sus súbditos. Prefirio insistir en las instituciones como las Sociedades Economicas. Según él, los miembros de las Sociedades "cooperan, por decirlo así, con el Gobierno en el importante ministerio de labrar la felicidad del Estado, es sin duda un objeto el más recomendable, lo debe ser en todos tiempos y países, y lo será singularmente para aquellas almas privilegiadas, a quienes ha tocado alguna vez con su fuego el amor de la patria ${ }^{26 "}$. Esta observación sobre el papel de la Sociedad Economica Matritense también insiste en un sentimiento que está al origen de la felicidad de la colectividad: el patriotismo. Como hombre de su tiempo, Jovellanos creía en la fuerza del sentimiento para cambiar la realidad, este motivaba la acción del ilustrado, como lo revela en su "Discurso dirigido a la Real Sociedad de Amigos del País de Asturias, sobre los medios de promover la felicidad de aquel principado":

"Pero cuando tomo la pluma para exponer mis reflexiones acerca de los medios de promover la felicidad de mi patria, iqué cúmulo de ideas y de esperanzas no atrae a mi imaginación un objeto tan grande y tan provechoso! Inflamado por el patriotismo, quisiera llegar de un vuelo hasta la cumbre de la felicidad que es mi objeto $[\ldots]^{\prime 27}$.

El individuo según lo imagina Jovellanos, aspira no a su propia felicidad, sino a la de sus semejantes a través de las instituciones creadas por la Monarquía. Pero como lo señala F. Baras Escolá, el "moralismo" y "voluntarismo" ostentados en esos discursos son rasgos que "lejos de denotar una actitud ingenua o idealista (como a veces se ha sugerido) son perfectamente coherentes con su filosofía social y con su proyecto político"28. Esta concepción del patriotismo se adecua con una ideología elitista: se trata de una sociedad en la que la búsqueda de la felicidad no es obra de la colectividad entera, sino de un pequeño grupo de "patriotas", preferentemente nobles, animados por sentimientos filantropicos ${ }^{29}$.

26. JOVELLANOS, G.M., 1951-56, BAE, vol. 50, "Discurso en la SE de Madrid", p. 29a.

27. JOVELLANOS, G.M., 1951-56, BAE, vol. 50, "Discurso dirigido a la Real Sociedad de Amigos del País de Asturias, sobre los medios de promover la felicidad de aquel principado", p. 439.

28. BARAS ESCOLÁ, F., 1993, p. 268.

29. Véase BARAS ESCOLÁ, F., 1993, que concluye que para Jovellanos, "La patria sugiere un anhelo de sociabilidad perfecta, en virtud del cual todos los conflictos internos del pais se resuelven satisfactoria e idealmente. Las clases populares se mantienen al margen de cualquier intervención decisiva en la organización de la vida pública. Ciertamente ésta debe transformarse, pero los agentes del cambio se reclutan en las filas de la misma clase dominante, y más especificamente de la nobleza terrateniente. De ahí el fondo conservador y exclusivista de aquel anhelo. La patria condensa el conjunto de los impulsos reformistas del gobernante "ilustrado".; ella es la expresión acabada de tales impulsos y, en consecuencia, dispone de un gran poder de convocatoria [...]. De este modo, Jovellanos sitúa la Patria en la conciencia "ilustrada" de la aristocracia, en la voz interior que le previene contra su propia degeneracion". 
En el terreno económico, la utilización de la palabra "felicidad" parece contener menos ambigüedades. Así, en el "Discurso dirigido a la Real Sociedad de Amigos del País de Asturias, sobre los medios de promover la felicidad de aquel principado", Jovellanos indicaba qué sentido se había de darle al término:

"Cuando digo que la sociedad debe procurar la felicidad de Asturias, ya se ve que no tomo esta palabra en un sentido moral. Entiendo aquí por felicidad aquel estado de abundancia y comodidades que debe procurar todo buen gobierno a sus individuos. En este sentido, la provincia más rica será la más feliz, porque en la riqueza están cifradas todas las ventajas políticas de un estado. Así pues, el primer objeto de nuestra Sociedad debe ser la mayor riqueza posible del Principado de Asturias" 30 .

Entonces, en los proyectos e informes economicos, el concepto se identifica siempre con el crecimiento productivo y la abundancia material. En el Informe sobre la ley agraria, Jovellanos concluía que con el desarrollo de la agricultura, "no se trata menos que de abrir la primera y más abundante fuente de la riqueza pública y privada; de levantar la nación a la más alta cima del esplendor del poder, y de conducir los pueblos confiados a la vigilancia de vuestra alteza al último punto de la humana felicidad"31. Sería ocioso multiplicar los ejemplos, solo notaremos que la felicidad siempre aparece como el resultado del fomento de tal o cual sector economico, y lo que vale para la agricultura, se repite para los transportes o la industria doméstica. Este desarrollo había de ser el resultado de la acciones del gobierno. Uno de los medios para alcanzar el pleno desarrollo era fomentar una educacion basada en los conocimientos prácticos:

"Pero sobre todo convendrá que se promuevan en Asturias los buenos estudios, y especialmente el de aquellas ciencias que se llaman útiles, por lo mucho que contribuyen a la felicidad de los estados"32.

Nada original en el marco del discurso ilustrado, pero la verdadera novedad en Jovellanos consistio en hacer de la felicidad no solo un valor colectivo sino tambien individual, y demostrar que la felicidad del "individuo economico" era compatible o más bien necesaria para alcanzar la felicidad colectiva o pública como entonces se decía. Así, el asturiano subrayaba, tanto en la educación como en la economía, el estrecho vínculo que unía las dos nociones. Lo prueban los dos ejemplos siguientes:

Bases para la formación de un plan general de instrucción pública: "Se propondrá como último fin de sus trabajos aquella plenitud de instrucción que pueda habilitar a los individuos del Estado de cualquiera clase y profesión que sean, para

30. JOVELLANOS, G.M., 1951-56, BAE, vol. 50, "Discurso dirigido a la Real Sociedad de Amigos del Pais de Asturias, sobre los medios de promover la felicidad de aquel principado", p. 443a.

31. JOVELLANOS, G.M., 1986, p. 330.

32. JOVELLANOS, G.M., 1951-56, BAE, vol. 50, "Discurso dirigido a la Real Sociedad de Amigos del Pais de Asturias, sobre los medios de promover la felicidad de aquel principado" p. 452b. 
adquirir su felicidad personal, y concurrir al bien y a la prosperidad de la nacion en el mayor grado posible ${ }^{33 "}$.

Correspondencia con don Manuel Godoy : "Conocerá [este gobierno] que los hombres tienen en su interés personal un estímulo bastante poderoso para buscar su felicidad particular, y dejará sobre la acción de este interés. Conocerá que el interés público es inseparable de este interés individual, y por consiguiente no se fatigará en dirigir éste para promover aquél" ${ }^{34}$.

La aspiración a la felicidad en Jovellanos es marcadamente individualista. Se valió muy poco del sintagma "felicidad pública" que tanto abundaba en los escritos de Campomanes por ejemplo. Así, es Iógico que el asturiano haya desarrollado en paralelo a su obra economica una reflexion ética sobre el concepto de felicidad individual.

\section{Una nueva etica}

Jovellanos no quedaba satisfecho con una significacion meramente material de la palabra y, en otros escritos, insistio en el contenido ético del concepto. En la "Memoria sobre educacion pública", preguntaba:

"Pero $i$ acaso la prosperidad está cifrada en la riqueza ? ¿ No se estimarán en nada las calidades morales en una sociedad ? ¿ No tendrán influjo en la felicidad de los individuos y en la fuerza de los estados? Pudiera creerse que no en medio del afán con que se busca la riqueza y la indiferencia con que se busca la virtud. Con todo, la virtud y el valor deben contarse entre los elementos de la prosperidad social" ${ }^{\prime 3}$.

En la misma obra indicaba que para una buena educación "se deberá hacer sentir a los jovenes que sólo por medio de la virtud podrán Ilegar a alcanzar aquella felicidad en pos de la cual los hombres, por una inclinación innata e inseparable de su ser, suspiran y se agitan continuamente" ${ }^{36}$. En la reflexion ética del asturiano, la virtud es imprescindible para alcanzar la felicidad. Y el concepto tiene ya un significado diferente del que tenía en la reflexion economica. En efecto, se asocia con la religion. La aspiracion a la felicidad es creación de Dios: $\operatorname{dad}^{\prime \prime 37}$.

"[...] el Criador imprimió a todos los entes animados el apetito de su felici-

Lo que explica que el hombre, "no podrá gozar ninguna especie de felicidad temporal que no esté acompañada de la esperanza de la felicidad eter-

33. JOVELLANOS, G.M., 1951-56, BAE, vol. 46, "Bases para la formación de un plan general de instrucción pública", p. 270a.

34. JOVELLANOS, G.M., 1951-56, BAE, vol. 86, "Correspondencia con don Manuel Godoy", p. 198a-b

35. JOVELLANOS, G.M., 1951-56, BAE, vol. 46, "Memoria sobre educación pública", p. 231b.

36. JOVELLANOS, G.M., 1951-56, BAE, vol. 46, "Memoria sobre educación pública", p. 261a.

37. JOVELLANOS, G.M., 1951-56, BAE, vol. 46, "Memoria sobre educación pública", p. 261a. 
na" ${ }^{38}$. Esta afirmación muestra que si el concepto tendio a secularizarse, no había perdido su contenido religioso ${ }^{39}$. Para Jovellanos, el mundo temporal quedaba subordinado al mundo sobrenatural ${ }^{40}$. Por otra parte, la felicidad que asociaba Jovellanos tan estrechamente con el desarrollo de la economía en sus escritos sobre el tema, a nivel ético, no suponía paradojicamente el bienestar material:

"[...] el Criador [...] haciendo que la felicidad naciese del ejercicio de la virtud, la puso al alcance de todos y la hizo independiente de la fortuna"41.

En este caso, la valoracion del individuo y de su intimidad justifica esta definicion de la felicidad, ya que "esta felicidad no es un bien que exista fuera de nosotros; [...] pues nadie es feliz sino el que está íntimamente persuadido que lo es [... $]^{\prime 42}$. Estas reflexiones le Ilevaron a valorar las clases humildes, tomando el topico moral de la felicidad de los pobres y actualizando su contenido:

"Pero la felicidad parece más dependiente de las ideas o sentimientos del ánimo, pues que suele hallarse en la mediana y aun en la humilde suerte, y suele andar muy distante de lo que se llama grande y alta fortuna. En este sentido también su estado será más accesible al hombre instruido, en cuyo arbitrio estarán más medios de conocer y alcanzar aquellas ideas y sentimientos de paz y de contento en que se hagan residir la felicidad" 43 .

Como lo apunto J.A. Maravall, a nivel ético, la felicidad individual se transforma "en virtud interior, de estructura moral más tradicional —renovando su carga estoica-, lo que viene a ser una manera de apelar a un control o medida conscientemente aceptada de las posibilidades del desarrollo de bienes externos ${ }^{44}$. La relatividad de la felicidad cuadra perfectamente con una concepción conservadora de la sociedad en la que cada uno puede ser feliz sin necesidad de ascenso social. Nos parece también corresponder con la ideología de "clase intermediaria". Por una parte esta se define como feliz, lo que autoriza una valoración de sus ideales de vida, ya que los que pretenden serlo exclusivamente a través del bienestar material no pueden alcanzar la felicidad. Por otra parte, suponiendo que la suerte humilde no es incompatible con la

38. JOVELLANOS, G.M., 1951-56, BAE, vol. 46, "Memoria sobre educación pública", p. 261b.

39. Sobre la secularización, véase, ÁLVAREZ DE MIRANDA, P., 1992, p. 273.

40. Ignacio Falgueras, en "Las ideas filosoficas de la llustracion", p. 141a, opina que "tanto el catolicismo, del que España a diferencia del resto de los países europeos habían hecho su tarea historica, como el realismo, que distingue nuestro modo de ver el mundo, impidieron a nuestros ilustrados compartir el ideal de emancipación respecto de lo sobre natural y la concepción utópica de la realidad".

41. JOVELLANOS, G.M., 1951-56, BAE, vol. 46, "Memoria sobre educación pública", p. 261a.

42. JOVELLANOS, G.M., 1951-56, BAE, vol. 46, "Memoria sobre educación pública", p. 261a.

43. JOVELLANOS, G.M., 1951-56, BAE, vol. 87, "Introducción a un discurso sobre el estudio de la economía civil", p. 17..

44. J.A. MARAVALL, 1973, p. 456. 
felicidad, se ahorran los remordimientos sobre la verdadera condición material de las clases inferiores.

El análisis de la idea de felicidad en la obra de Jovellanos permite precisar los contornos de su proyecto político y situarlo respecto al pensamiento de su tiempo. Primero, su idea de la acción política es bastante parecida a la de sus predecesores. Para él las reformas que permitirán alcanzar la felicidad serán obra de la élite administrativa y económica, y no de la nación como se afirmará más tarde en las Cortes de Cádiz. En este aspecto, el asturiano sigue el modelo del Antiguo Régimen y es no en nada precursor del liberalismo político. En el terreno de la economía, su definicion de la felicidad es mucho más moderna. La asocia estrechamente con el desarrollo economico. Pero otra vez, Ios actores principales serán los terratenientes, como lo demuestra en el Informe sobre la ley agraria. A nivel etico, esta concepción de la felicidad cuadra con lo que F. Baras Escolá denomino "el proyecto jovellanista de restauración política de la aristocracia". Se trataba de proponer una nueva ética de clase a la nobleza. Ésta había de ser, en el marco del sistema administrativo y político vigente, el grupo que haría acceder, por su patriotismo, el país entero a la felicidad, entendiendo este concepto ante todo como sinonimo de desarrollo económico. Este desarrollo sería también el resultado de la acción de individuos activos -entiendase aquí una élite economica como se sugiere en el Informe sobre la ley agraria y no todos los habitantes del país- que buscarían su interés personal, nada incompatible con la felicidad general. Por otra parte, la actitud de esta nueva clase tenía que ser ejemplar. Así, su felicidad no podía residir únicamente en el goce de placeres materiales, sino que había de tomar en cuenta valores tradicionales como la dimension espiritual del hombre, lo que le permitía reactivar y dar nuevo contenido a una nocion antiguamente asociada con la nobleza, la virtud ${ }^{45}$.

Este estudio demuestra que el léxico forjado por la llustracion podía muy bien servir para defender posiciones moderadas o conservadoras. En el terreno lingüístico hay que separar claramente el lexico de la semántica, lo que en términos historicos significa que no siempre existe una perfecta adecuación entre vocabulario e ideología. Las mismas palabras pueden servir para metas diferentes. No pensamos sin embargo que en el caso preciso de Jovellanos se trate de una adulteracion de la llustracion ya que esta "no es una doctrina ni tampoco una escuela o corriente filosofica homogenea, sino más bien una etapa en el pensamiento moderno" ${ }^{46}$. Por otra parte, se plantea el problema de la "continuidad" ideologica entre los reformadores del Antiguo Régimen y los liberales de principios del siglo XIX. La permanencia del vocabulario tiene siempre que ser considerada con precauciones y como

45. Sería en este caso interesante comparar la concepción de Jovellanos con el discurso LXXIII del Censor.

46. Falgueras, I, "Ideas filosoficas de la llustracion", p. 127a. 
lo advertimos al principio, el léxico no es un signo infalible de identidad social y política. En efecto, se siguio esgrimiendo la palabra "felicidad" en las Cortes de Cádiz y más tarde en el periodo de la Regencia, pero, ya no se trataba de justificar la monarquía absoluta y la accion de una élite administrativa, sino de echar los cimientos de un nuevo sistema político y social que significaba el triunfo de la burguesía y de sus valores que la nobleza había ido integrando progresivamente ${ }^{47}$.

\section{Bibliografía}

ÁlVAREZ DE MIRANDA, P. 1992. Palabras e ideas, el léxico de la llustración temprana en España (1680-1760), Madrid.

ARMOGATHE, J.R. 1973. "Néologie et idéologie dans la langue française au 18e siècle", Dix-Huitième Siècle 5, pp. 17-28.

BARAS ESCOLÁ, F. 1993. El reformismo politico de Jovellanos (nobleza y poder en el siglo XVIII), Zaragoza.

DOMERGUE, L. 1997. "Le tournant libéral, notes sur Jovellanos et El informe sobre la Iey agraria", Ville et campagne en Espagne au XVIIle, pp. 35-60, Paris.

DUBOIS, J. 1962. Le vocabulaire politique et social en France de 1869 à 1872, Paris.

DUBOIS, J. 1969. "Lexicologie et analyse d'énoncé": Cahiers de lexicologie XV, Paris, pp. 115-126.

Falgueras, I., 1991. "Ideas filosóficas de la Ilustración", Torre de los Lujanes 18, Madrid, pp. $127-149$

FOUCAULT, M. 1969. L'archéologie du savoir, Paris

GOMEZ URDÁN̄EZ, G. 1996.. "Reflexiones sobre la revolución burguesa en España. Una aproximación a los orígenes, ideario y práctica del pensamiento liberal", Brocar 20, Logroño, pp. 327-346.

JOVELLANOS, G.M., 1986. Informe sobre la ley agraria, Madrid

JOVELLANOS, G.M. 1951-1955. Obras completas. Madrid.

LAPESA, R. 1968. "Ideas y palabras: del vocabulario de la llustración al de los primeros liberales": Asclepio XVIII-XIX, Madrid, pp. 189-218.

MAINGUENEAU, D. (DIR.) 1995. Les analyses du discours en France: Langages 117, Paris.

MARTI, M. 1997. "Théories économiques, libéralisme et pensée politique dans El informe de la ley agraria", L'Espagne du XVIIle siècle, Saint Étienne, pp. 189-204.

MATORÉ, G., 1953. La methode en lexicologie, Paris.

47. Sobre los aspectos económicos de esta integración véase Gomez Urdánez, G., 1996, pp. 334 337 
MARAVALL, J.A. 1974. "La idea de felicidad en el programa de la llustración": Mélanges offerts à Charles Vincent Aubrun, Paris, pp. 425-462.

MAUZI, R. 1960. L'idée de bonheur dans la littérature et la pensée française au XVIIle siècle. Paris.

PEIRA, P. 1977. "Estudio lexicológico de un campo nocional: Libertad, igualdad, y felicidad, en la España de la regencia de María Cristina": BRAE LVII, pp. 259-294.

RO BIN, R. 1973a. H istoire et linguistique. Paris.

RO BIN, R., 1973b. "Les historiens devant le champ de la linguistique, nouveau gadget ou constitution de l'objet discursif ?": Dix-Huitième Siècle 5, pp. 111-118.

SEOANE, M.C. 1968. El primer lenguaje constitucional español (las Cortes de Cádiz). Madrid.

SO U BEYRO UX, J. 1984. "El discurso de la llustración sobre la pobreza. Análisis de una formación discursiva": Nueva Revista de Filología Hispánica, T. XXXIII, n²1, México, pp. 115-132.

SO UBEYROUX, J. 1997. "Recherches sur la notion de progrès dans la littérature pragmatique espagnole de la seconde moitié du XVIIle siècle": Mouvement, progrès, périodisation, Cahiers du GRIAS 5, Saint Étienne, pp. 9-27. 
